\title{
Range of activities by "Bashkirenergo" LLC to improve the reliability of overhead power lines during heavy icing
}

\author{
I. Y. Bayramov ${ }^{1}$, A. Y. Elizariev ${ }^{1} \&$ A. R. Valeev ${ }^{2}$ \\ 1 "Bashkirenergo" LLC, Russia \\ ${ }^{2}$ Ufa State Aviation Technical University, Russia
}

\begin{abstract}
The paper considers the issue of expertise of "Bashkirenergo" LLC and methods of wires and lightning-conductors of overhead power lines deicing. We have made a duration analysis of the icy season for LLC "Bashkirenergo" energy network and its influence on the reliability of power equipment. We have undertaken an analysis of current activities to prevent and eliminate icing accidents. Using the vast experience of LLC "Bashkirenergo" and academic basis of the Ufa State Aviation Technical University we have developed our own comprehensive contingency plans to prevent and eliminate icing emergencies. These plans include - 1. Preparation and further updating of zoning plans depending on glazed crust thickness; 2. Preparation and further updating of zoning plans depending on recurrence and intensity of conductor galloping; 3. Implementation of active and passive methods of deicing; 4. Implementation of active and passive methods of limitation of conductor galloping; 5. Implementation of computer-aided icing surveillance systems; 6. Staff training and development. The above plans to enhance the reliability of overhead power lines during intensive icing periods will help to improve ice melting systems, ensuring prompt data communication from respective sections of high-voltage lines and extending melting areas. Based on analytical investigations proven by experimental studies we may draw necessary conclusions on the most effective deicing methods and means in the territory of Bashkortostan. All this together have allowed for the increase in reliability of electrical networks of "Bashkirenergo" LLC during the autumn and winter season.

Keywords: ice, transmission lines, map of ice thickness, de-ice systems, galloping control, wireless monitoring, staff trainings.
\end{abstract}




\section{Introduction}

Despite long-term efforts of specialists, ice accidents in the electric networks of many power systems are still the most severe and occasionally cause power outages. These accidents are evoked by the ice, rime or wet snow accumulated on transmission wires combined with the wind load which is called "glaze-wind situation" (fig. 1).

The deleterious effects of wind and ice loads have a significant impact on reliability of power system of the Republic of Bashkortostan.

Long-term statistics shows that in the Republic of Bashkortostan mean icing season lasts for 133 days. The wind and ice loads most often occur in Belebey electric networks, Beloretsk electric networks, Sibai electric networks, Kumertau electric networks - the boundary areas of the Republic of Bashkortostan with Chelyabinsk and Orenburg Oblasts and the Republic of Tatarstan. But climatic changes trend points that ice loads regions are shifted toward the center of the Republic.

The last severe ice accidents on overhead transmission lines of "Bashkirenergo" such as breaking support poles, insulators as well as wires and ground wires occurred in 2001-2006.

Over the years substantial amount of universities in Russia investigates the various aspects of improving reliability of electric networks under wind and ice loads. The Ufa State Aviation Technical University (USATU) is one of these universities, and it has been working closely with "Bashkirenergo" for decades.

Based on vast experience of "Bashkrienergo" and theoretical basis of USATU the integrated system for ice loads accidents prevention and elimination was developed [1]. It includes:

1. Development and further updating of the regional map of ice thickness;

2. Development and further updating of galloping region division map;

3. Utilizing de-ice and anti-ice systems;

4. Utilizing active and passive galloping control methods;

5. Utilizing wireless monitoring of overhead power lines;

6. Staff trainings and development.
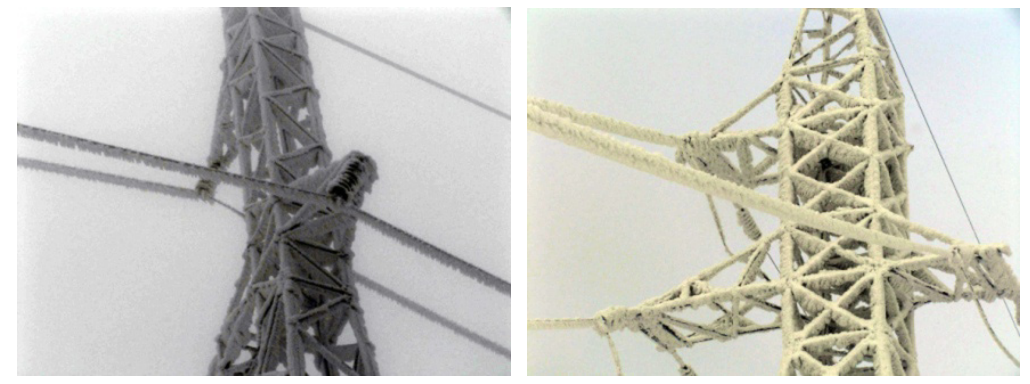

Figure 1: $\quad$ Ice cover on transmission towers and wires. 


\section{Development of the maps of wind and ice loads}

In 2011 ice loading map of the Republic of Bashkortostan was updated by specialists of USATU and third-party companies (fig. 2). Data of ice loads and overhead transmission lines outages on wires and ground wires of "Bashkirenergo" since 1957 to 2010 have served as a reference base for this work.

Development of ice loads maps is based on two classical methods of AllUnion Electric Power Research Institute (VNIIE):

- the principle of the altitude dependence of absolute elevations above sea;

- estimate extreme ice thicknesses using limiting distributions.

Combined application of these two methods increases the reliability of regional map of ice loads [2].

Also in 2011 in USATU the galloping region division map of the Republic of Bashkortostan was developed for the first time (fig. 3).

In developing these galloping maps main data sources were data of outages caused by flashover during galloping wires $6-500 \mathrm{kV}$ for a period of 1955 up to 2010. Data of outages have been analyzed and regions with intense galloping were localized.

But imperfection of currently monitoring systems for galloping wires and lack of objective data about galloping identifies the need to also revise electric networks where no galloping was registered by operating crew. Revision was carried out with factors that have the most significant impact on galloping repeat rate and intensity. In regions where galloping had been registered the possibility of wires flashover was checked out. The galloping region division map was developed basing on all above mentioned data $[3,4]$.

The developed regional maps are used by electric network operating crew to analyse the compliance of construction and elements of overhead transmission lines on the Republic of Bashkortostan to above mentioned maps and current regulatory and technical documentation.

Recommendations to transmission lines projects elaboration and technological innovations application during the design, operation and carrying out transmission line have been worked out by specialists of USATU.

\section{De-ice and anti-ice systems}

"Bashkirnergo" gives particular attention to improvement of technical operations to prevent icing accidents and limit their consequences. Ice melting is the general technical operation to remove or reduce ice accretion (de-icing method). In electric networks of "Bashkirenergo" about 185 ice-meltings are performed per year.

Currently, 327 melting schemes are operational in networks $35-110 \mathrm{kV}$ and three DC converters are used. For the previous years, 25 short-circuiting switches have been installed [1]. 


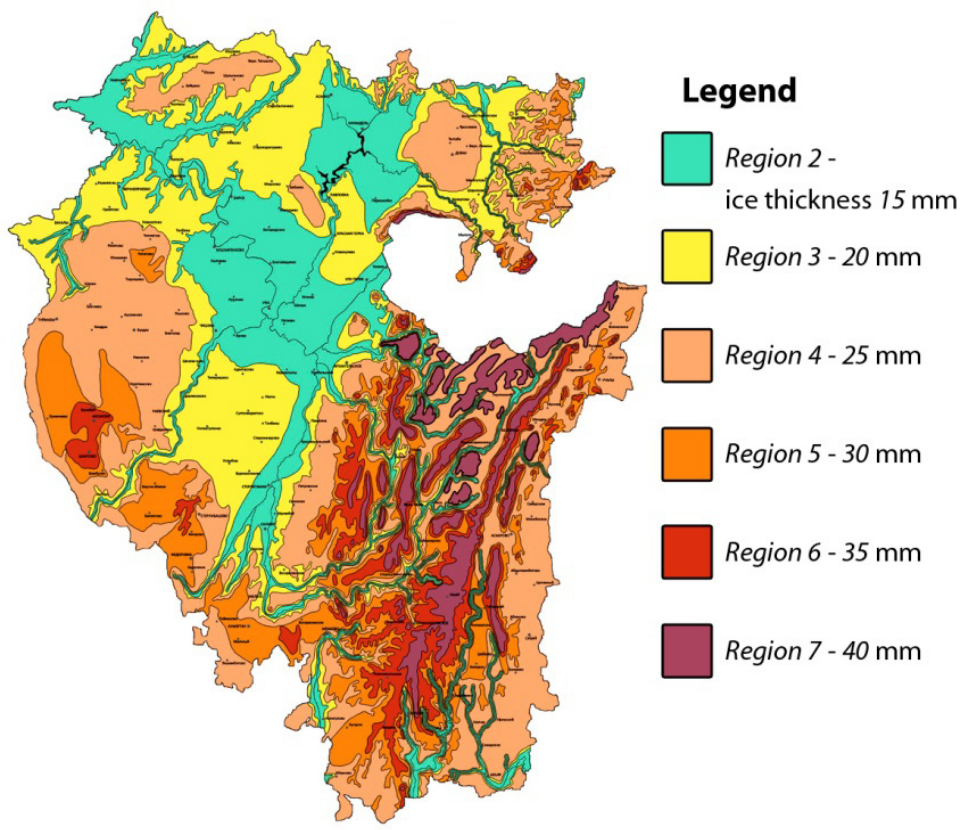

Figure 2: $\quad$ Regional map of ice thickness.

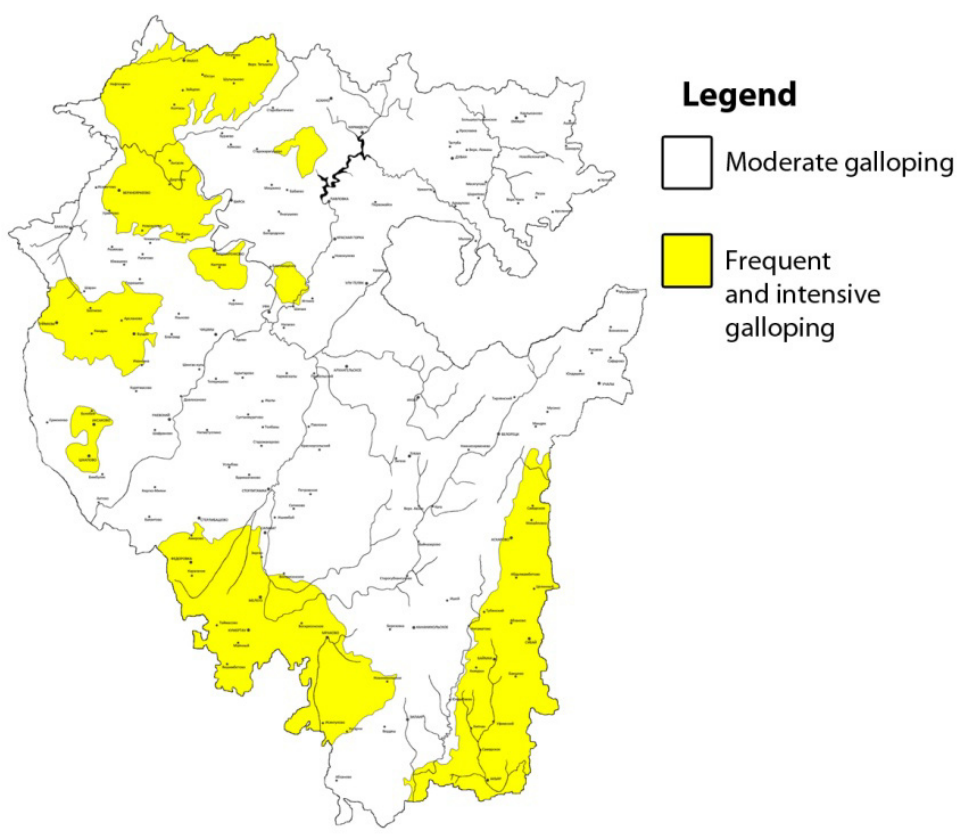

Figure 3: Galloping region division map. 
A simple and cost-effective way to solve problem of using substation grounding mat as a rectifier unit operating grounding mat was developed and patented by specialists of "Bashkirenergo". But within this method direct current is flowing into the solidly earthed neutral of power transformer. That leads to an increase of transformer open-circuit current and iron loss. The essence of the method is that grounding ice-melting switches is used as an external grounding. These switches by construction are traditional three-phase switches. On one side switch contacts are connected with transmission line wires, On the other side contacts are grounding. Grounding ice-melting switches are installed at a distance from substation. Distance may vary; necessary condition is absence of metallic connection between grounding maps of substation and switch.

Along with de-icing methods, passive anti-icing methods are used in electric networks.

"Bashkirenergo" carries out planned activity to install counterweights on transmission lines in icy regions (fig. 4).

A wire with reduced ice adhesion was developed and patented by specialists of "Bashkirenergo". The experimental researches of this wire are being carried out. Some or all conductors of outer layer of the wire are made of steel, interleaving with aluminium conductors. Surface of wire will heat up by current due to high electrical resistance of steel. Temperature is dependent on the current in the wire. Snow or ice will not adhere to the wire if the temperature of the wire is higher than the temperature of ambient air.

Experimental research of innovative anti-ice wires, developed by other companies is also carried out in the electric networks of "Bashkirenergo". Functional tests in conditions of extreme ice loads will show if innovative wires provide less ice accretion and greater electric load than traditional wires. That will reduce costs of melting ice and disconnecting transmission lines.
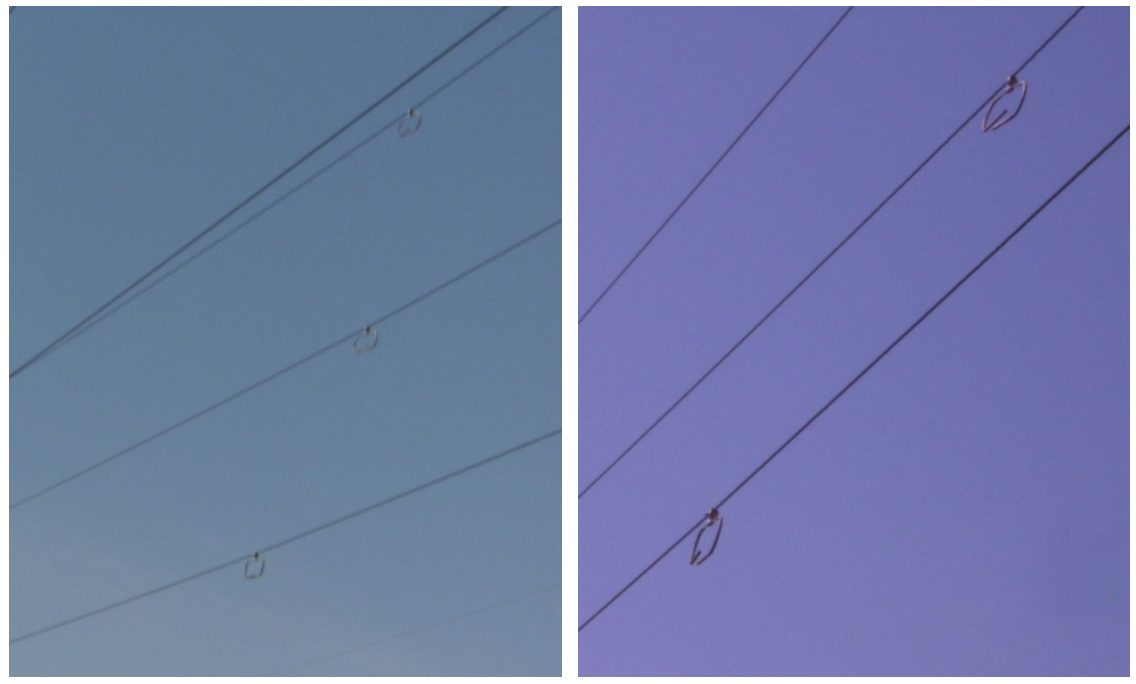

Figure 4: Counterweights on transmission lines. 


\section{Overhead lines galloping control}

Power engineers of the Republic of Bashkortostan are paying a great deal of attention to control galloping of transmission and distribution lines. They use both passive and active control methods.

Passive methods are:

- design overhead lines with regard to the regional weather loads;

- estimate the maximum expected amplitude of galloping wires;

- control sufficient phase-to-phase spacing so that clashing during galloping are prevented;

- expert evaluation of the hazard of conductor galloping.

However, only passive methods are insufficient to control galloping. Passive methods do not decrease dynamic loads during galloping. Dynamic loads cause serious damage with broken conductors, insulators, hardware and transmission towers.

Ice-meltings and reconstruction of transmission lines are carried out to reduce galloping amplitude. But application of interphase spacers is the most effective and the most economical method to control galloping (fig. 5).
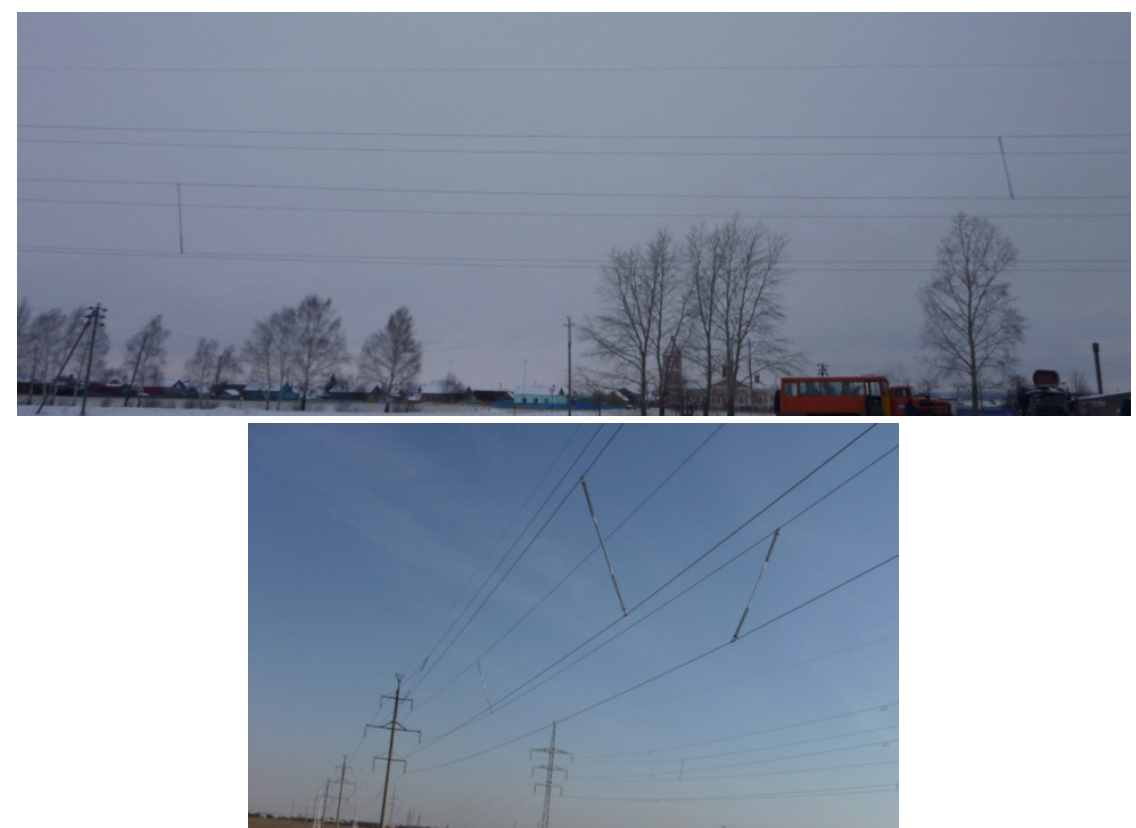

Figure 5: Interphase spacers on transmission line.

Interphase spacers are used to retain wires within the design limits by installing polymer insulators between wires or bundled conductors, thus preventing conductors from striking each other during galloping. Interphase spacer reduces galloping amplitude and concerned dynamic loads on transmission lines. 
There are over 600 interphase spacers in the electric networks of "Bashkirenergo" [1].

An interphase spacer that used energy of galloping wires to dumping ice cover was developed in "Bashkirenergo". These interphase spacers have been already mounted on experimental lines.

\section{Monitoring of overhead power lines}

To protect overhead lines the weather data along with the data of type and amount of ice on the transmission line are needed. Only with reliable data efficiency of de-ice and anti-ice methods is reached. To measure this data Automated Information System of Control for Ice Load (AISCIL) system are installed on transmission lines. About 20 AISCIL systems of different vendors are mounted in the electric network of "Bashkirenergo". "Bashkirenergo" has developed and patented its own AISCIL control system. We are working now on power supply and data transmission improvement and upgrading.

Own software for AISCIL was developed and embedded to Dispetcher Operative-Information Complex (fig. 6). This software is used by power engineers to perform de-icing methods on power transmission lines.

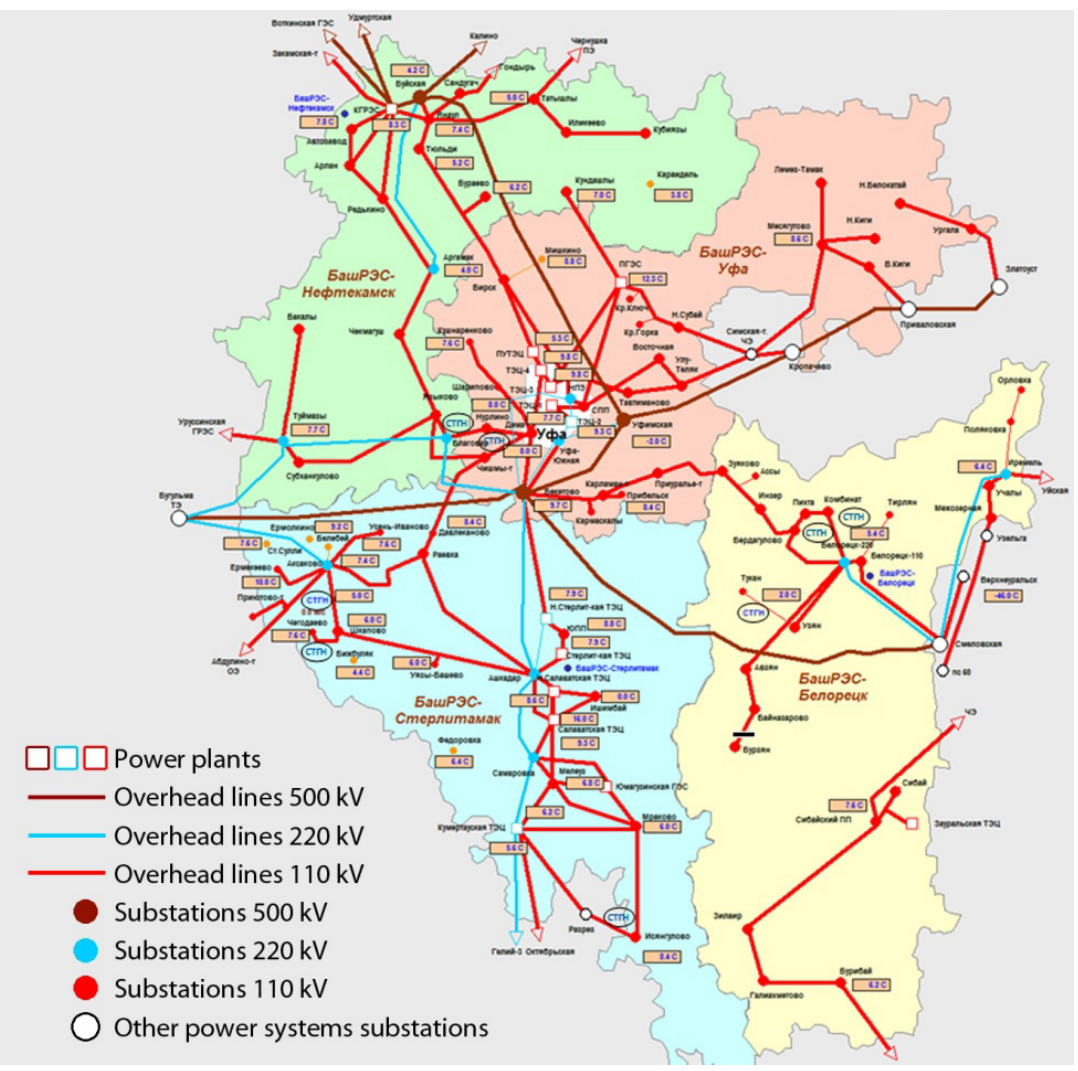

Figure 6: Wireless monitoring system. 
Annual appointments devoted to the energy equipment operation within the extreme ice and wind loads are held. Power engineers of "Bashkirenegro" and other power systems, equipment vendors and scientists are invited to participate in the meeting. Urgent problems of previous autumn and winter season are solved at the conference.

During the year in the training centre of "Bashkirenergo" technical personnel is trained on the topic of the wind and ice impact on overhead transmission lines.

\section{Conclusions}

The above mentioned integrated system for ice loads accidents prevention and elimination improves ice-melting system. It improves timely transmission data of lines condition and increase melting coverage area. Experimental research on physical models and on existing overhead lines confirms the theoretical investigations. This allows us to define the most effective means to deal with icing on the territory of the Republic of Bashkortostan.

All this together has allowed the reliability of electrical networks of "Bashkirenergo" to be increased during the autumn and winter season.

\section{References}

[1] Shevelev, Y.P., Bayramov, I.Y. \& Elizariev, A.Y., Range of activities by "Bashkir power distribution networks" LLC to improve reliability of overhead lines during intensive icing. Proc. of the All-Russia sci. conf. "Ice and wind effects on overhead lines - solutions”, eds. M.B. Guzairov et al., USATU: Ufa, pp. 25-29, 2012.

[2] Ismagilov, F.R., Maksimov, V.A., Volkova, T.Y., Elizariev, A.Y., Valeev, A.R., Regional map of ice thickness of the territory of the Republic of Bashkortostan. Electrical complexes and systems, eds. F.R. Ismagilov et al., USATU: Ufa, pp. 7-13, 2011.

[3] Elizariev, A.Y., Volkova, T.Y., Maksimov, V.A., Valeev, A.R., Zoning of the territory of the Republic of Bashkortostan on galloping repeat rate and intensity. Electrical complexes and systems, eds. F.R. Ismagilov et al., USATU: Ufa, pp. 43-47, 2012.

[4] Ismagilov, F.R., Valeev, A.R. \& Volkova, T.Y., Developing climatic region division maps of the territory of the Republic of Bashkortostan. Proc. of the All-Russia sci. conf. "Ice and wind effects on overhead lines - solutions", eds. M.B. Guzairov et al., USATU: Ufa, pp. 22-24, 2012. 